\title{
Optimizing Bio-sand Filter (BSF) for Maximum Thermotolerant Coliform (TTC) Removal from Drinking Water in West Bank
}

\author{
Ahmed I.A Saya'Ra* \\ Department of Environmental studies, Al-Quds University, Palestine, 2021
}

*Corresponding Authors: Ahmed I.A Saya'Ra, Department of Environmental studies, Al-Quds University, Palestine, 2021

\begin{abstract}
There are about 297,900 Palestinian lives in 532 residential areas in Area c of Palestine (Jarrar, 2019). Many of them rely on rain harvesting into cisterns during winter to fulfill their needs of drinking water. For instance, in Massafer Yatta results of water quality from cisterns showed contamination levels that is ranging from 20-100 CFU/100ml. The Bio-sand filter (BSF) have been prompted extensively for water treatment in households in developing countries. In present study the influence of 9 operating parameters on BSF efficiency for Thermotolerant coliform (TTC) removal was investigated. Results analysis showed that $5 \mathrm{~h}$ residence time, and media age more than one month were significant with P-values of 0.0439 and 0.0089 , respectively. Charge volume, turbidity and using different cistern to fill BSF had no significant influence. Although the 5 h residence time was significant, it was not sufficient to minimize TTC below the drinking water permissible level of 10 CFU/100ml when influent water had 500 CFU/100ml TTC. In addition to, the use of $5 \mathrm{~h}$ residence time has led to a reduced filter age around 4 years, the filter efficiency to remove TTC started to gradually decrease after that. The use of sand of $0.18 \mathrm{~mm}$ effective size was significant with a $P$-value of 0.0016. While the temperature itself and inflow rate had no significant influence, the interaction of temperature and effective size was significant with a P-value of 0.0459. Elevated temperature up to $33{ }^{\circ} \mathrm{C}$ was found to negatively interfere BSF ability to remove TTC when the filter has effective size of $0.23 \mathrm{~mm}$. The influent TTC count had a positive significant effect on the effluent BSF TTC with a P-value of 0.0004. The use of $23 \mathrm{~h}$ residence time showed the most significant influence among all operation parameters with a $P$-value $<0.0001$. The study concluded that the most important operation parameters for BSF to remove $99.8 \%$ TTC are $23 \mathrm{~h}$ residence time and $0.18 \mathrm{~mm}$ sand effective size. The study recommended to design a BSF that produces more than $20 \mathrm{~L}$ to be used once every $23 \mathrm{~h}$ and to replace the top of sand every 4 years at maximum.
\end{abstract}

\section{INTRODUCTION}

There are around 1.1 billion people worldwide lack access to safe drinking water. This lack of access combined with insufficient water supplies is responsible for occurrence of 4 billion cases of global diarrheal diseases (Sobsey et al., 2008). More than half a million children die from diarrhea each year (Kumar et al., 2020). In the occupied Palestinian territories, about $12.3 \%$ population are off access to public water supply (Mahmoud et al., 2018). Diarrhea in the territories is a major cause of outpatient visits and hospitalizations (Elamreen et al., 2007). According to the Vulnerability Profile Project (VPP) there are about 297,900 Palestinian in 532 residential areas in area c lives without access to public water grid (Jarrar, 2019). Residents of these areas subsist on herding and non-mechanized agriculture; they rely on rain harvesting into cisterns during winter to fulfill their needs of water that is contaminated with domestic animal's organic wastes. The available database from Comet-Me (Community Energy Technology-Middle East) have showed Thermotolerant Coliform (TTC), water contamination levels, ranging from $20-100 \mathrm{CFU} / 100 \mathrm{ml}$ in drinking water cisterns.

The Bio-sand filter (BSF) had been prompted extensively for water treatment in households in developing countries. It has been introduced in at least 36 countries worldwide with more than half a million people using this technology (Elliott et al., 2008). This filter is easy to operate, maintain, affordable, durable, manufactured using local materials, zero energy consumption and sustainable (Kubare \& Haarhoff, 2010). BSF seems to be an appropriate technology for biological water treatment in residential areas of Palestinian territories. In this paper the optimum BSF operation conditions were characterized and optimized based on the design of experiment (DOE) provided by Design Expert 
software. The influence of 9 operating parameters on BSF efficiency for Thermotolerant coliform (TTC) removal was investigated. These parameters were residence time, charge volume, media age, turbidity, changing water source, temperature, sand effective size, influent TTC counts, and inflow rate.

\section{MeThOdOLOGY}

As per the Center for Affordable Water and Sanitation Technology (CAWST) specifications, the following (Fig.1) show BSF design. The filter is about $90 \mathrm{~cm}$ height plastic cylinder pipe, it is diameter is $25 \mathrm{~cm}$. At the bottom $10 \mathrm{~cm}$ layer of small gravel is installed followed by another $10 \mathrm{~cm}$ larger gravel layer and $40 \mathrm{~cm}$ layer of sieved and treated sand.

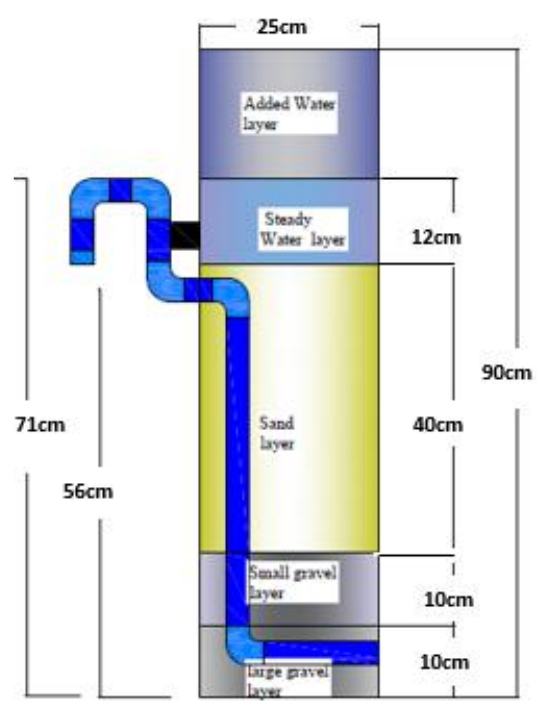

Fig1. BSF design (units are displayed by $\mathrm{cm}$ )

\subsection{Residence Time, Charge Volume, Media Age, Water Source and Turbidity Characterization Experiment:}

In this experiment Regular Two Levels factorial design $2^{5-1}$ with 4 center points was used to characterize the influence of residence time, charge volume, media age, water source and turbidity. Residence time low level was assigned $1 \mathrm{~h}$ while the high level was $5 \mathrm{~h}$, the center point was approximated $3 \mathrm{~h}$. Charge volume levels were 4, 6 and 8L. Media age levels were 1, 37 and 73 months. Turbidity levels were 1, 10 and 20 NTU. Two different cisterns of harvest 1 and harvest 2 were used to characterize the influence of changing water source on filter treatment efficiency.

\subsection{Temperature, Residence Time, Charge Volume, Effective Size and Inflow Rate Characterization Experiment:}

In this experiment a replicated Regular Two Levels factorial design $2^{5-1}$ was used without center points. For temperature, constant low level of $25{ }^{\circ} \mathrm{C}$ inside the cave and a fluctuating high level of average $33^{\circ} \mathrm{C}$ outside the cave were used. The low and high levels of effective size were 0.18 and $0.23 \mathrm{~mm}$. Inflow rate levels were irrigation meter as low and manual charge as high levels. Residence time low level was $2 \mathrm{~h}$ and $4 \mathrm{~h}$ as high level. The charge volume low and high levels were 6 and $8 \mathrm{~L}$.

\subsection{Residence Time Optimization with Influent Count and Media Age:}

Response Surface Method (RSM) and Behnken Box Design (BBD) were used in this experiment in order to obtain a mathematical equation that can be used to inform farmers how many times they should fill the filter per day and how long they should wait before complete water treatment is ensured based on TTC concentration in their cistern. Residence time had 3 levels of 1, 12 and 24h. Media age levels were 4, 40 and 77 months. Influent TTC counts were 10, 500 and 1000 CFU/100ml.

\subsection{Analytical Methods}

TTC analysis was performed using DelAgua kit (manual version 5.0). This analysis is based on the membrane filtration method of TTC specified by the WHO in annex 6 of guidelines for drinking water quality. Turbidity was measured by nephelometric tube method provided with DelAgua kit. 
Porosity, pore volume of the filter sand and effective size and uniformity coefficient (UC) were measured based on CAWST guidelines.

\section{RESULTS AND DISCUSSION}

\subsection{Residence Time, Charge Volume, Media Age, Water Source and Turbidity Characterization Experiment:}

The analysis of results using design expert software (Analysis of Variance ANOVA) showed that only residence time and media age were significant with P-values of 0.0439 and 0.0089 , respectively. Charge volume, turbidity and changing water source had no significant influence (Fig.2).
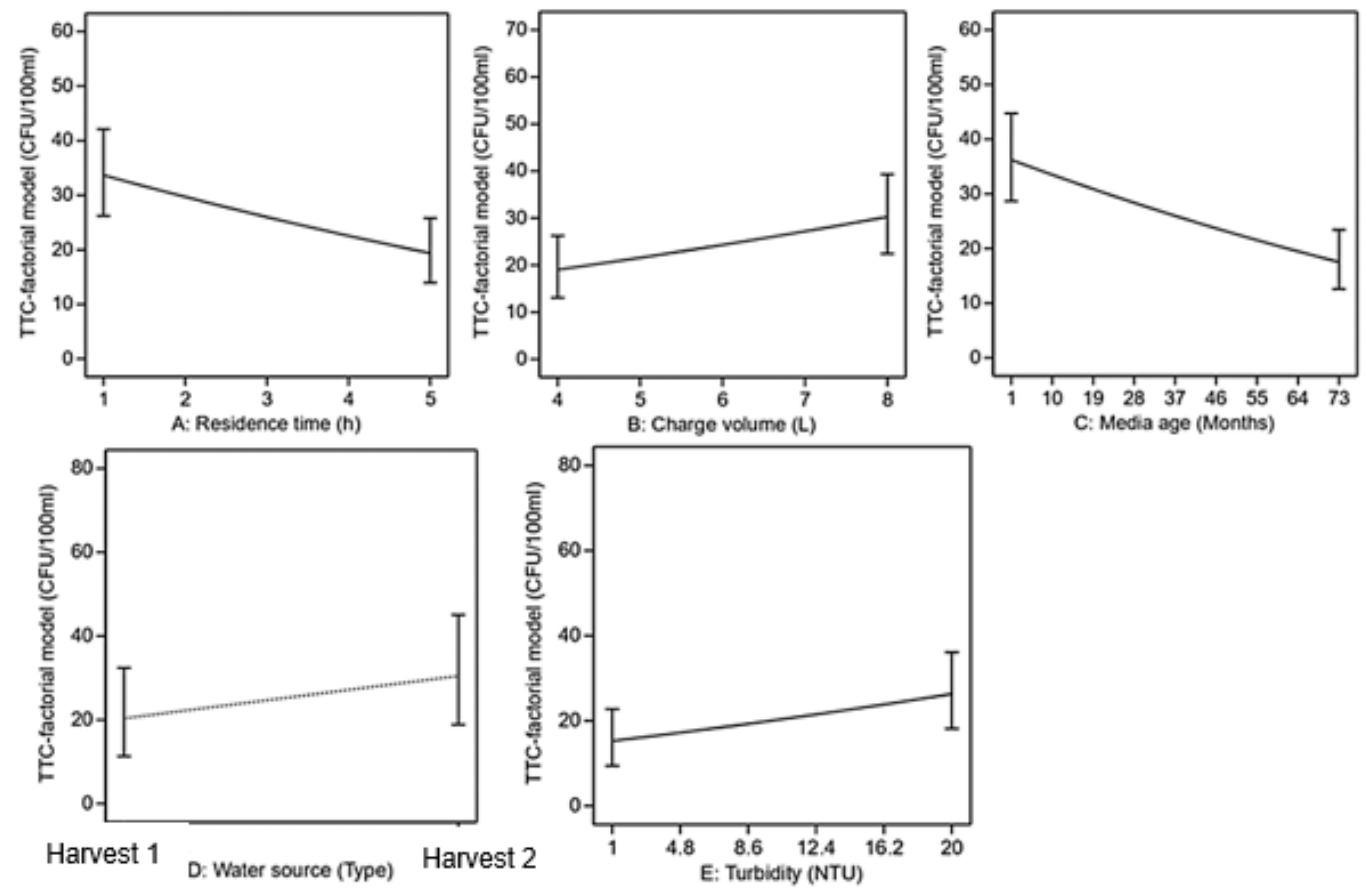

Fig2. Residence time, charge volume, media age, water source and turbidity influence on TTC removal from BSF

In this experiment residence time was compared for the levels of 1,3 and $5 \mathrm{~h}$. This was enough to detect the signal $(\Delta y 50)$. CAWST recommends BSF operation with a minimum of $5 \mathrm{~h}$ after each fill. The BSF elimination of pathogens is based on their contact time with sand particles. The longer water retention in sand media increases the opportunity to adsorb or trap more pathogens. Despite that, when water source had TTC concentration up to $500 \mathrm{CFU} / 100 \mathrm{ml}$, $5 \mathrm{~h}$ residence time operation format was not completely effective. In this experiment the results of TTC after BSF were higher than the reasonable water quality limits of $0-10 \mathrm{CFU} / 100 \mathrm{ml}$. The average TTC in effluent samples was $22.62 \pm 4.3$ $\mathrm{CFU} / 100 \mathrm{ml}$.

Although increasing charge volume did not show a significant change on TTC removal, this was not a contradiction to its significant role in filtration process that was described by previous studies. On the contrary, referring to current BSF design in methods, the total sand volume in BSF was approximately calculated 19.6L. At completion of all experiments, sand porosity for each filter was measured after completely drying sand samples. The average filters porosity in this experiment was 0.43 , this is about 8.5L water that can be retained in $19.6 \mathrm{~L}$ of sand. This explains the insignificance of charge volume in this study. Whether the filter was filled 4, 6 or 8 liters, the whole batch was, approximately speaking, contained in filters sand bed.

Media age was also significant with P-value of 0.0089 . Most previous studies investigated this factor in range of 1 to few months. This study has compared media age up to 6 years. The findings here were consistent with most previous works which emphasized an increased BSF efficiency after one month of operation. BSF is assumed to remain effective at ages up to many years. In the current study it was found that BSF can effectively reduce TTC by $96 \%$ and produce reasonable water quality $(<10$ $\mathrm{CFU} / 100 \mathrm{ml}$ ) in media age range of $28-46$ month. Further investigation is required to ensure efficiency of BSF beyond this range when it is operated in intervals of 1-5 $\mathrm{h}$ residence time (Fig.3). 


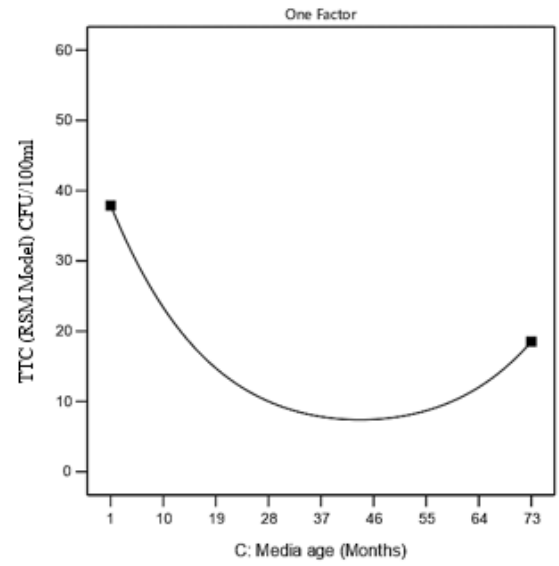

Fig3. Influence of media age on TTC Removal when residence time is 1-5h

There were no significant effects that resulted from changing the water source to a different cistern as long they have relative TTC concentration (about $500 \mathrm{CFU} / 100 \mathrm{ml}$ in this case). This factor was included because farmers in area $\mathrm{c}$ usually have few cisterns to fill during rainy season. The main cistern near the household is filled from other cisterns when it is empty.

There was no significant influence for turbidity in range of 1-20 NTU on BSF removal efficiency. However, turbidity reduction to acceptable limits $(<5 \mathrm{NTU})$ by BSF is important to ensure water is safe to drink.

The Design Expert software helps to predict optimal values of factors based on the regression model generated from results analysis. For this purpose, factors were chosen within their range of low and high level in the experiment. The most optimum solution was suggested as $5 \mathrm{~h}$ residence time, $7.77 \mathrm{~L}$ charge volume and 53.3 months media age. This was sufficient to produce TTC of 4 CFU/100ml.

\subsection{Temperature, Residence Time, Charge Volume, Effective Size and Inflow Rate Characterization Experiment}

The analysis of variance ANOVA showed that effective size and residence time had a significant influence on BSF TTC removal with P-value of 0.0016 and 0.0238 , respectively. While temperature, inflow rate and charge volume were insignificant factors (Fig.4).
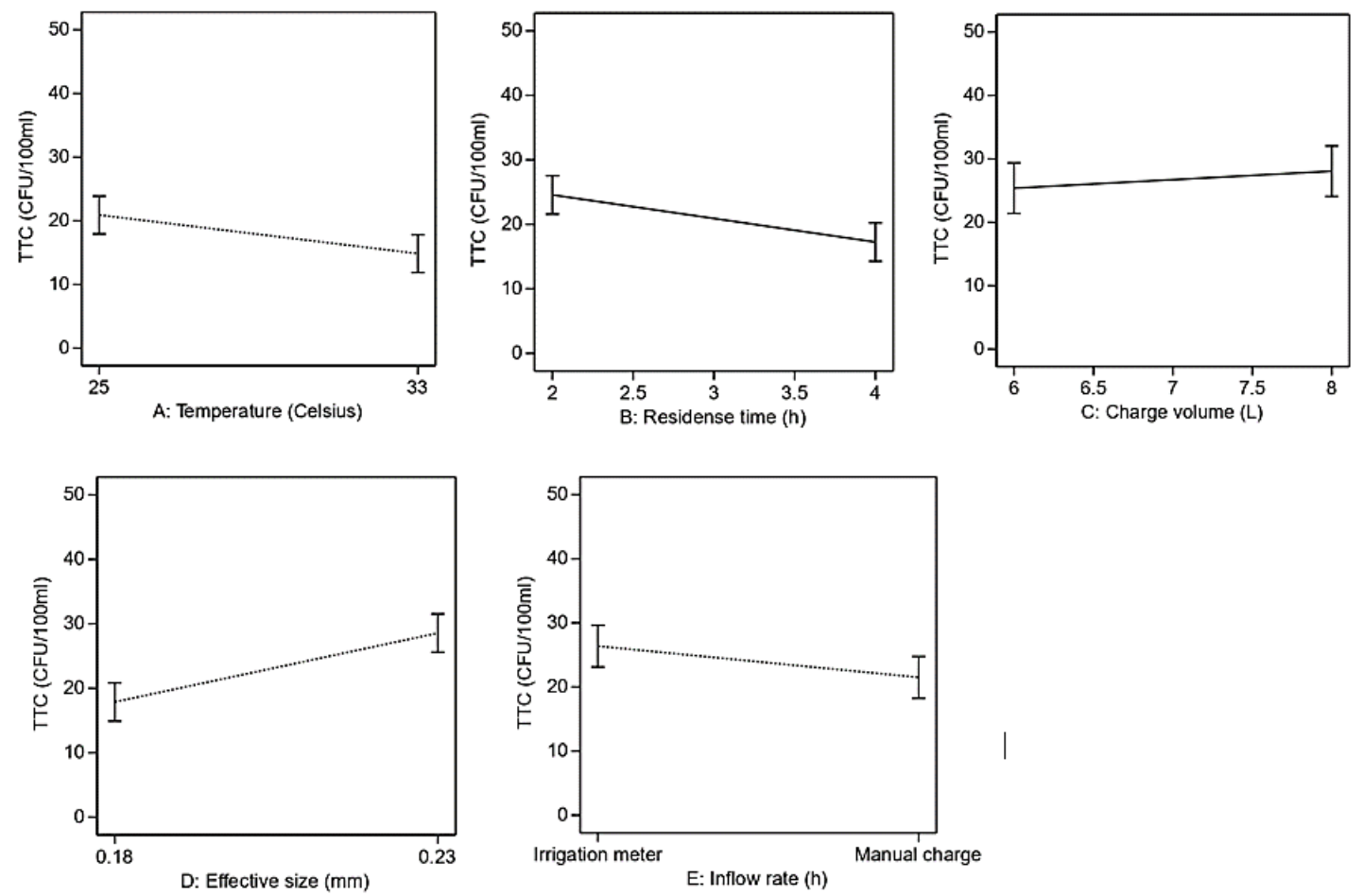

Fig4. Temperature, residence time, charge volume, effective size and inflow rate influence on BSF TTC removal 
Temperature influence on BSF was investigated as constant and fluctuating in this experiment. Whether filters were operated at constant temperature of $25^{\circ} \mathrm{C}$ or a fluctuating of average $33^{\circ} \mathrm{C}$, there was no variation on BSF TTC removal. While the temperature itself was not significant, it showed an interaction with effective size (Fig.5). At $25{ }^{\circ} \mathrm{C}$ both 0.18 and $0.23 \mathrm{~mm}$ had same influence on TTC removal. On the other hand, at $33^{\circ} \mathrm{C}, 0.18 \mathrm{~mm}$ was significantly more effective to remove TTC. (Bai et al., 2016) investigated the effect of temperature on the transport of suspended particles in pore space of material. They found that when temperature increases it accelerates the irregular movement of suspended particles and reduces their migration velocity, this can be attributed to the narrower pores in $0.18 \mathrm{~mm}$ than $0.23 \mathrm{~mm}$.

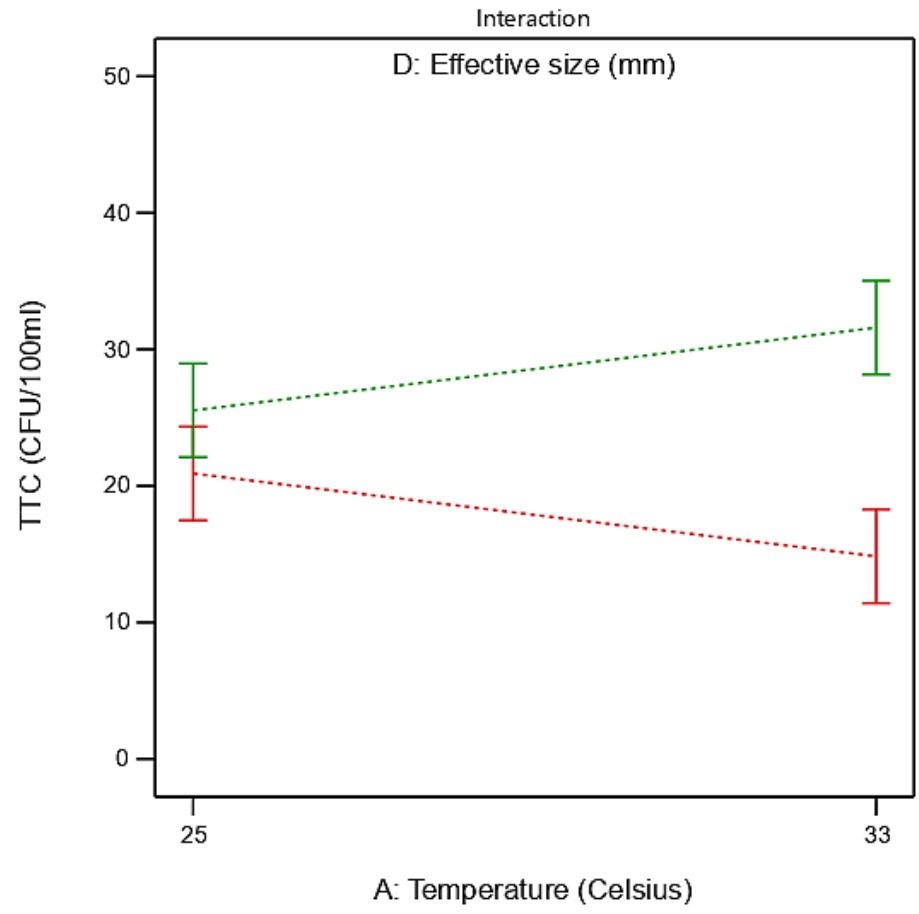

Fig5. Temperature and effective size interaction

The residence time was a gain significant when it was increased from 2 to $4 \mathrm{~h}$. The reason behind using these two levels in this experiment was that 1 to $5 \mathrm{~h}$ is considered long for a nonlinear factor without a middle point. Charge volume significance did not appear as well, this is due to the sufficient sand pore space that can contain 6 and 8L. Changing the inflow rate from manual charge to automatic irrigation meter did not produce any significance. This is probably due to the mechanical action of diffuser placed above the standing water layer which maintain regular water inflow on sand top layer.

\subsection{Residence Time Optimization with Influent Count and Media Age}

In the first experiment it was concluded that residence time of 5 hours and media age over 1 month have a significant positive influence on BSF TTC removal (minimized TTC by $50 \Delta \mathrm{y}$ ). The significant model calculated desired charge volume as $7.77 \mathrm{~L}$. It was also concluded in the second experiment that finer sand of $0.18 \mathrm{~mm}$ effective size improves TTC removal. In this experiment the previous significant findings were taken into consideration. The charge volume was adjusted at $7 \mathrm{~L}$, starting media age was upgraded to 4 months and the $0.18 \mathrm{~mm}$ effective size BSF was chosen as start filter besides the 40- and 77-months filters.

Seventeen runs were designed in this experiment to mathematically model the influence of influent TTC count, media age and residence time on BSF efficiency. In this case residence time, Influent TTC count, Residence time-influent count interaction were significant model terms with P-value 0.0006, 0.0004, 0.0006 , respectively. The influence of media age was insignificant with P-value of 0.4295, this is due to including filters older than 4 months. The RSM graphical presentation (Fig.6) shows the interaction of residence time and influent count. The graph surface slice show that increasing residence time to $24 \mathrm{~h}$ was necessary to keep BSF efficiency to remove high count to $1000 \mathrm{CFU} / 100 \mathrm{ml}$. The color of the surface slice changed from blue to green at that point to visualize the difference. Fig. 7 presents the 
interaction of media age and influent count, there was no clear change on the slice surface or color. This is also driving the conclusion that media age more than one moth will have same efficiency of TTC removal when selected residence time is up to $24 \mathrm{~h}$.

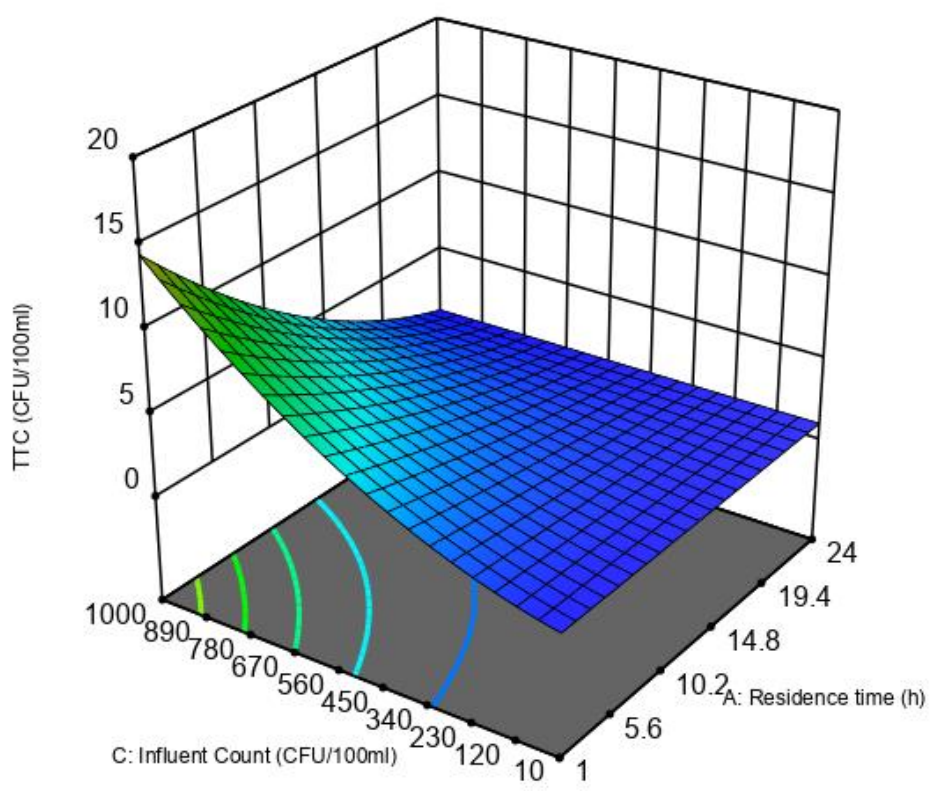

Fig6. Interaction of Influent count and Residence time



Fig6. Interaction of influent count and media age

The review of fit statistics and diagnostics of this experiment showed $R^{2}$ value of 0.9224 . The significant RSM model explains very well the data. Adjusted and Predicted $\mathrm{R}^{2}$ were in reasonable agreement of 0.8758 and 0.7652 . Their difference was less than 0.2. The RSM model of this experiment specified optimum conditions to maximize TTC removal by BSF as the following: residence time of 23 hours, media age 29.9 months and influent count of $475.9 \mathrm{CFU}$. The result is $99.8 \%$ TTC removal as the response TTC result under these conditions is $0.953 \mathrm{CFU} / 100 \mathrm{ml}$.

\section{CONClusion}

1. The 5-hour residence time was enough to produce $\Delta y$ change of $50 \mathrm{CFU} / 100 \mathrm{ml}$. Despite that, when water source had TTC concentration up to $500 \mathrm{CFU} / 100 \mathrm{ml}$ this operation format was not 
completely effective. In this case the results of TTC after BSF were higher than the reasonable water quality limits of $0-10 \mathrm{CFU} / 100 \mathrm{ml}$. The average TTC in effluent samples was $22.62 \pm 4.3$ $\mathrm{CFU} / 100 \mathrm{ml}$.

2. BSF media age is more efficient for TTC removal after one month of filter setup. the BSF operation format of once every 1-5 hours residence time may result in filter age reduction to less than 4-6 years. On the contrary the BSF operation format of 12-24 h extends filter age to more than 6 years. This is due to the operation of the filter less frequently (1-2 times per day).

3. There is no significant effect on BSF TTC removal when filter is filled from a different water source as long, they both have relatively equal TTC concentration.

4. BSF is excellent for turbidity removal in range up to $50 \mathrm{NTU}$. Turbidity of 1-20 NTU is within filter capability for this purpose.

5. The optimum charge volume of BSF is the volume of sand pore space. BSF media should be designed to contain approximately all charged water volume to ensure complete water treatment.

6. Smaller effective sand size has expressed a significant effect on TTC removal from BSF. Together with uniformity coefficient should be considered among critical factors to improve BSF efficiency.

7. Whether BSF is filled manually or using an irrigation meter, this should not be of great concern when operating the filter in rural areas that lack electricity or water grid infrastructure.

8. Small sand effective size of about $0.18 \mathrm{~mm}$ is necessary to maintain high filter efficiency when temperature rises to $33{ }^{\circ} \mathrm{C}$. Filters of larger sand effective size cannot produce reasonable water quality (TTC $<10 \mathrm{CFU} / 100 \mathrm{ml}$ ) in warm climates.

9. The optimum BSF operation residence time should be $23 \mathrm{~h}$ when raw water has TTC up to 1000 CFU/100ml.

\section{RECOMMENDATIONS}

The BSF can be an effective sustainable solution for water treatment in area c of West Bank. The filter installation materials are cheap and available from local materials. It requires as minimum periodic maintenance. The present research recommends BSF design and operation as the following:

1. The size of BSF should be related to the family size and number of users. BSF should be ideally operated once per day. If it is still insufficient to meet family needs, the filter can be used twice a day with a residence time of 12 hours. For this reason, bigger filters which can produce more than $20 \mathrm{~L}$ are more desirable.

2. Since BSF media efficiency to remove TTC reduces with time, particularly after 4 years, it is recommended to replace the top $10-20 \mathrm{~cm}$ of sand column after this period.

3. The average temperature in West Bank may reach $33^{\circ} \mathrm{C}$ during summer. For this it is recommended to install filters with sand of $0.18 \mathrm{~mm}$ effective size to minimize the adverse effects of temperature on BSF efficiency for TTC removal.

\section{REFERENCES}

[1] Sobsey, M., Stauber, C., Casanova, L., Brown, J., \& Elliott, M. (2008). Point of Use Household Drinking Water Filtration: A Practical, Effective Solution for Providing Sustained Access to Safe Drinking Water in the Developing World. Environmental Science \& Technology, 42(12), 4261-4

[2] Kumar, S., Haikerwal, A., \& Saxena, S. K. (2020). Epidemiology of Water-Associated Infectious Diseases. In Water-Associated Infectious Diseases (pp. 19-25). Springer, Singapore. 267. doi: 10.1021/es702746n

[3] Mahmoud, N., Hogland, W., Sokolov, M., Rud, V., \& Myazin, N. (2018). Assessment of rainwater harvesting for domestic water supply in palestinian rural areas. MATEC Web of Conferences, 245, 06012. doi: $10.1051 /$ matecconf/201824506012

[4] Elamreen, F. H. A., Abed, A. A., \& Sharif, F. A. (2007). Detection and identification of bacterial enteropathogens by polymerase chain reaction and conventional techniques in childhood acute gastroenteritis in Gaza, Palestine. International journal of infectious diseases, 11(6), 501-507. 
[5] Elliott, M., Stauber, C., Koksal, F., DiGiano, F., \& Sobsey, M. (2008). Reductions of E. coli, echovirus type 12 and bacteriophages in an intermittently operated household-scale slow sand filter. Water Research, 42(1011), 2662-2670. doi: 10.1016/j.watres.2008.01.016

[6] Kubare, M., \& Haarhoff, J. (2010). Rational design of domestic biosand filters. Journal Of Water Supply: Research And Technology-Aqua, 59(1), 1-15. doi: 10.2166/aqua.2010.008

[7] Bai, B., Long, F., Rao, D. and Xu, T., 2016. The effect of temperature on the seepage transport of suspended particles in a porous medium. Hydrological Processes, 31(2), pp.382-393.

[8] Jarrar, S. Adaptation under occupation : climate change vulnerability in the Occupied Palestinian Territory.(2019). Retrieved 26 December 2019, from http://www.alhaq.org/publications/15261.html

Citation: Ahmed I.A Saya'Ra, “Optimizing Bio-sand Filter (BSF) for Maximum Thermotolerant Coliform (TTC) Removal from Drinking Water in West Bank.", International Journal of Research in Environmental Science (IJRES), vol. 7, no. 2, pp. 28-35, 2021. Available: DOI: http://dx.doi.org/10.20431/2454-9444.0702003

Copyright: (C) 2021 Authors. This is an open-access article distributed under the terms of the Creative Commons Attribution License, which permits unrestricted use, distribution, and reproduction in any medium, provided the original author and source are credited. 